Ismet Gocer*, Serdar Ongan **

\section{The Relationship between Inflation and Interest Rates in the UK: The Nonlinear ARDL Approach}

\begin{abstract}
This study reconsiders the Fisher effect for the UK from a different methodological perspective. To this aim, the nonlinear ARDL model recently developed by Shin et al. (2014), is applied over the periods of 1995M1-2008M9 and 2008M10-2018M1. This model decomposes the changes in original inflation series as two new series: increases and decreases in inflation rates. Hence, it enables us to examine the Fisher effect in terms of increases and decreases in inflation separately. The empirical findings support asymmetrically partial Fisher effects for the UK in the long-run only for the first period. Additionally, this study attempts to describe and introduce a different version of the partial effect concept for the first time for the UK.
\end{abstract}

Keywords: Fisher effect, Nonlinear ARDL, the UK's treasury bond rates

JEL Classification: E40, E43, G12.

\section{Introduction}

Understanding the mechanism and relationship between interest rates and inflation is crucially important for the efficient and timely economic decisions for economic actors instituting monetary policy (Praščević and Ješić, 2019). Irving Fisher, one of the leading neo-classical economists, tested this relationship for the UK and the USA in
* Department of Econometrics, Adnan Menderes University,

Aydin, Turkey

E-mail (corresponding author): ismetgocer@gmail.com

${ }^{* *}$ Department of Economics, St. Mary's College of Maryland, St. Mary's City, MD, USA

E-mail:

songan@smcm.edu 
his 1930 study $^{1}$ and found strong correlations running from the changes in inflation to the changes in nominal interest rates. Fisher (1930) postulates that there is a one-for-one positive relationship between the nominal interest rate and the expected inflation rate, assuming the constancy of real interest rates over time.

In the most common form of below Fisher equation, $i_{t}$ is the nominal interest rate, $r_{t}^{e}$ is the ex-ante real interest rate, $\pi_{t}^{e}$ is the expected inflation rate and $\varepsilon_{t}$ is the error term.

$$
i_{t}=r_{t}^{e}+\pi_{t}^{e}+\varepsilon_{t}
$$

Under the assumption of rational expectations, the Fisher equation can now be rewritten in the following form, since the rate of expected inflation equals the actual inflation rate $\left(\pi_{t}^{e}=\pi_{t}\right)$.

$$
i_{t}=\alpha+\beta \pi_{t}+\varepsilon_{t}
$$

In Eqn.2, if the estimate of $\beta$ equals to 1, this supports the evidence of a full Fisher effect, referring to a one-for-one relationship by Fisher (1930). If $\beta$ is higher or lower than 1, this supports a partial Fisher effect (Bayat, Kayhan and Tasar, 2018). In this positive linear form of the equation, rises in inflation rates lead to increases in nominal interest rates, whereas falls in inflation rates reduce them, signifying full or partial Fisher effects (Fabris, 2018).

However, the relationship between inflation and nominal interest rate may not be linear (symmetric) and instead may be nonlinear (asymmetric) (Ajaz, 2019). In other words, increases and decreases in inflation may affect the nominal interest rates differently (asymmetrically). Therefore, the empirical methodology of this study is based on this possible nonlinearity (asymmetry) and is different from the previous studies using the common linear representation of Fisher equation in Eqn.2. To this aim, the nonlinear ARDL model, recently developed by Shin et al. (2014), is applied for testing the Fisher effect.

In this model, the changes in inflation rate $\left(\pi_{t}\right)$ are decomposed into $\pi_{t}^{+}$and $\pi_{t}^{-}$, delineating the increases and decreases in inflation rates respectively derived from $\pi_{t}$. Hence, this model enables us to examine the Fisher effects in terms of increases and decreases in inflation rates separately. Because the effects of $\pi_{t}^{+}$on the nominal interest rates can be more or less than the effects of $\pi_{t}^{-}$. If both $\pi_{t}^{+}$and $\pi_{t}^{-}$are significantly positive this will signify full (if $\pi_{t}^{+}=\pi_{t}^{-}=1$ ) or partial (if $\pi_{t}^{+}$ and $\pi_{t}^{-} \neq 1$ ) Fisher effects. The usage of this model also enables us to understand

\footnotetext{
1 The Theory of Interest Fisher (1930)
} 
whether $\pi_{t}^{+}$and $\pi_{t}^{-}$have symmetric or asymmetric effects on the nominal interest rates. For instance, if $\pi_{t}^{+}$and $\pi_{t}^{-}$are the same in sign and size, this will signify symmetric effects on the nominal interest rates. If they are different in sign or the same in sign but different in size, this will signify asymmetric effects. Through the combination of symmetry-asymmetry and the Fisher effect, if significantly positive $\pi_{t}^{+}$and $\pi_{t}^{-}$are the same in size, this will signify symmetrical Fisher effects. Similarly, if significantly positive $\pi_{t}^{+}$and $\pi_{t}^{-}$are different in size, this will signify asymmetrical Fisher effects.

Another potential output of this model is that it may enable us to describe and introduce a different and new version of the partial Fisher effect considering the signs and significances of $\pi_{t}^{+}$and $\pi_{t}^{-}$instead of 1 as a threshold parameter (denotes one-for-one relationship). In other words, if either $\pi_{t}^{+}$or $\pi_{t}^{-}$is significantly positive, this may signify a new version of the partial Fisher effect. The concept of introduced partiality here is considered to be the singular parametric effects of $\pi_{t}^{+}$or $\pi_{t}^{-}$on the nominal interest rates separately. If $\pi_{t}^{+}$is significantly positive, this will signify that increases in inflation lead to increases on nominal interest rates, thereby meaning singular (partial) Fisher effects only from $\pi_{t}^{+}$. Similarly, if $\pi_{t}^{-}$significantly positive, this will signify that decreases in inflation lead to decreases on nominal interest rates, thereby meaning singular (partial) Fisher effects only from $\pi_{t}^{-}$. The nonlinear ARDL model with its decomposed variables may mathematically provide us an approach to the partiality of the Fisher effect from this perspective. However, this new concept should be considered as a different methodological perspective of approaching the partiality of the Fisher effect that supports the classical approach that refers to 1 . In this study, we also use 1 for the decision of partial and full Fisher effects.

In this study, we examine the Fisher effect from this perspective by applying the nonlinear ARDL model for the United Kingdom (UK). This country may provide us a unique case study because the Bank of England (BOE) has adopted inflation targeting policy by using interest rates as an operational target since 1992. Hence, this country's past and ongoing monetary policy is based on the relationship between interest rates and inflation rates.

Some scholars tested the Fisher effect for the UK by using different methodologies but results of the findings of these studies are mixed. For instance, Andrade and Clare (1994) used the Kalman Filter and cointegration for the UK and found no evidence supporting the Fisher effect for this country. Similarly, Yuhn (1996) applied the unit root test and cointegration and found no evidence of the Fisher effect for the UK. Ghazali \& Ramlee (2003) tested the Fisher effect by applying the Autoregressive Fractionally Integrated Moving Average (ARFIMA) model and 
also found no evidence of the Fisher effect for the country. On the other hand, Peng (1995), Bajo-Rubio, Díaz-Roldán, \& Esteve (2010), Toyoshima and Hamori (2011) and Granville \& Mallick (2004) used cointegration and found evidence of the Fisher effect for the UK. Likewise, Lardic \& Mignon (2003) applied Fractional cointegration and found the same result for the country. Fahmy \& Kandil (2003) used the VAR Cointegration and found the evidence of the Fisher effect for the UK. Similarly, Panopoulou (2005) applied the autoregressive distributed lag (ARDL) and found support for the Fisher effect for the UK.

The rest of this paper is organized as follows. Section 2 describes empirical methodology. Section 3 presents the empirical results. Lastly, Section 4 gives concluding remarks. The data set of the study is presented in appendix.

\section{Empirical Methodology}

First, we decompose the changes in inflation $\left(\pi_{t}\right)$ in Eqn.2 into $\pi_{t}^{+}$and $\pi_{t}^{-}$. The decomposition is constructed with the following concept of partial sum process:

$\pi_{t}^{+}=\sum_{j=1}^{t} \Delta \pi_{j}^{+}=\sum_{j=1}^{t} \max \left(\Delta \pi_{j}, 0\right)$

$\pi_{t}^{-}=\sum_{j=1}^{t} \Delta \pi_{j}^{-}=\sum_{j=1}^{t} \min \left(\Delta \pi_{j}, 0\right)$

where $\pi_{t}^{+}$and $\pi_{t}^{-}$are the partial sum process of increases and decreases in $\pi_{t}$.

Second, we follow Shin et al. (2014) and transform the model in Eqn.2. into the following nonlinear ARDL model.

$\Delta i_{t}=\alpha_{0}+\sum_{j=1}^{p} \alpha_{1 j} \Delta i_{t-j}+\sum_{j=0}^{q} \alpha_{2 j} \Delta \pi_{t-j}^{+}+\sum_{j=0}^{n} \alpha_{3 j} \Delta \pi_{t-j}^{-}+\alpha_{4} i_{t-1}+\alpha_{5} \pi_{t-1}^{+}+\alpha_{6} \pi_{t-1}^{-}+\varepsilon_{t}(5)$

In this equation, $\alpha_{2 j}$ and $\alpha_{3 j}$ correspond to $\pi_{t}^{+}$and $\pi_{t}^{-}$respectively for the estimates of the short-run Fisher effects. Similarly, $\alpha_{5}$ and $\alpha_{6}$ correspond to the same changes in inflation for the estimates of the long-run Fisher effects. Hence, significantly positive $\alpha_{5}$ and $\alpha_{6}$ will indicate that a rise in inflation increases the nominal interest rate and a fall reduces it, signifying a full (if $\alpha_{5}=\alpha_{6}=1$ ) or partial (if $\alpha_{5}$ and $\alpha_{6} \neq 1$ ) Fisher effect in the long-run. It is same for short-run Fisher effects between $\alpha_{2 j}$ and $\alpha_{3 j}$. To our best knowledge, this is the first study applying the nonlinear ARDL model to test the Fisher effect for the UK from this perspective. 
We first apply Bai-Perron (2003) sequential structural breaks test to define the break dates of the series. The results of this test indicate that we should analyse the series in two different time frames as 1995M5-2008M9 and 2008M10-2018M1 since 2008 is a critical game changing year in global economies.

\section{Empirical Results}

Before processing the model, we must confirm whether the series are cointegrated in the long-run. To this aim, we apply bounds testing. The results of this test are reported in Table 1.

Table 1: Test Results of Bounds Testing

\begin{tabular}{|c|c|c|c|c|c|c|c|c|}
\hline & \multicolumn{8}{|c|}{ Critical Values } \\
\hline & \multirow[t]{2}{*}{ k } & \multirow[t]{2}{*}{ F stat. } & \multicolumn{3}{|c|}{ I0 Bound } & \multicolumn{3}{|c|}{ I1 Bound } \\
\hline & & & $10 \%$ & $5 \%$ & $1 \%$ & $10 \%$ & $5 \%$ & $1 \%$ \\
\hline (1) & 2 & $3.93^{c}$ & 2.63 & 3.55 & 4.13 & 3.35 & 4.38 & 5.00 \\
\hline (2) & 2 & $4.32^{c}$ & 3.38 & 3.88 & 4.99 & 4.02 & 4.61 & 5.85 \\
\hline (3) & 2 & $5.57^{\mathrm{b}}$ & 3.17 & 3.79 & 5.15 & 4.14 & 4.85 & 6.36 \\
\hline (4) & 2 & $6.94^{\mathrm{a}}$ & 3.38 & 3.88 & 4.99 & 4.02 & 4.61 & 5.85 \\
\hline (5) & 2 & $6.97^{a}$ & 3.38 & 3.88 & 4.99 & 4.02 & 4.61 & 5.85 \\
\hline (6) & 2 & $4.63^{\mathrm{a}}$ & 1.99 & 2.27 & 2.88 & 2.94 & 3.28 & 3.99 \\
\hline
\end{tabular}

Note: $a, b$ and $c$ denote statistical significances at $1 \%, 5 \%$ and $10 \%$ levels respectively. The optimal lags were automatically selected by using the Modified Akaike Information Criterion. $\Delta$ denotes the first differences of the series. 1,2 and 3 in parentheses represent the period of 1995M5-2008M9 and give the interest rates in different maturities: (1): 1-year treasury bond rates, (2): 5-years treasury bond rates, (3): 10-years treasury bond rates. 4,5 and 6 in parentheses give the same maturity interest rates for the period of 2008M10-2018M1.

Our calculated statistics, which are above the upper bounds at $1 \%, 5 \%$ or $10 \%$ significances, indicate that the series are cointegrated in the long-run. Hence, we can estimate the nonlinear ARDL model. The estimates of the model in the longrun and short-run are reported in Panels A and B in Table 2. 
Table 2: Estimation of the Interest Rate - Inflation Relationship (Nonlinear)

\begin{tabular}{|c|c|c|c|c|c|c|c|c|c|c|c|c|}
\hline \multirow[b]{3}{*}{ Var. } & \multicolumn{6}{|c|}{ 1995M1-2008M9 } & \multicolumn{6}{|c|}{$2008 \mathrm{M} 10-2018 \mathrm{M} 1$} \\
\hline & \multicolumn{2}{|c|}{ (1) } & \multicolumn{2}{|c|}{ (2) } & \multicolumn{2}{|c|}{ (3) } & \multicolumn{2}{|c|}{ (4) } & \multicolumn{2}{|c|}{ (5) } & \multicolumn{2}{|c|}{ (6) } \\
\hline & Coef. & Prb. & Coef. & Prb. & Coef. & Prb. & Coef. & Prb. & Coef. & Prb. & Coef. & Prb. \\
\hline & \multicolumn{12}{|c|}{ Panel A: Long Run } \\
\hline$\pi_{t}^{+}$ & $0.59^{\mathrm{a}}$ & 0.00 & $0.71^{\mathrm{a}}$ & 0.00 & $0.85^{\mathrm{a}}$ & 0.00 & $-0.08^{a}$ & 0.00 & $-0.30^{a}$ & 0.00 & $-0.24^{a}$ & 0.00 \\
\hline$\pi_{t}^{-}$ & $0.83^{a}$ & 0.00 & $0.95^{\mathrm{a}}$ & 0.00 & $1.08^{\mathrm{a}}$ & 0.00 & $-0.02^{b}$ & 0.02 & $-0.10^{a}$ & 0.00 & 0.01 & 0.64 \\
\hline \multirow[t]{2}{*}{ Constant } & $7.35^{\mathrm{a}}$ & 0.00 & $7.22^{\mathrm{a}}$ & 0.00 & $7.73^{\mathrm{a}}$ & 0.00 & $0.69^{a}$ & 0.00 & $2.45^{\mathrm{a}}$ & 0.00 & $4.03^{\mathrm{a}}$ & 0.00 \\
\hline & \multicolumn{12}{|c|}{ Panel B: Short Run } \\
\hline$\Delta i_{t-1}$ & $0.41^{\mathrm{b}}$ & 0.03 & $0.65^{a}$ & 0.00 & $0.38^{b}$ & 0.04 & $0.58^{a}$ & 0.00 & $0.40^{\mathrm{b}}$ & 0.02 & $0.47^{a}$ & 0.00 \\
\hline$\Delta i_{t-2}$ & $0.41^{\mathrm{b}}$ & 0.03 & $0.61^{a}$ & 0.00 & $0.41^{\mathrm{b}}$ & 0.03 & $0.63^{\mathrm{a}}$ & 0.00 & $0.53^{\mathrm{a}}$ & 0.00 & $0.60^{a}$ & 0.00 \\
\hline$\Delta i_{t-3}$ & $0.43^{b}$ & 0.02 & - & - & $0.66^{a}$ & 0.00 & $0.60^{\mathrm{a}}$ & 0.00 & $0.71^{\mathrm{a}}$ & 0.00 & $0.64^{\mathrm{a}}$ & 0.00 \\
\hline$\Delta i_{t-4}$ & $0.38^{c}$ & 0.05 & $0.75^{a}$ & 0.00 & $0.38^{b}$ & 0.04 & $0.59^{a}$ & 0.00 & $0.68^{a}$ & 0.00 & $0.72^{\mathrm{a}}$ & 0.00 \\
\hline$\Delta \pi_{t}^{+}$ & - & - & - & - & $0.54^{b}$ & 0.03 & $0.20^{\mathrm{b}}$ & 0.01 & - & - & - & - \\
\hline$\Delta \pi_{t-1}^{+}$ & - & - & $-0.85^{a}$ & 0.00 & $-1.00^{a}$ & 0.00 & $0.16^{a}$ & 0.00 & $0.53^{a}$ & 0.00 & - & - \\
\hline$\Delta \pi_{t-2}^{+}$ & - & - & $-0.54^{b}$ & 0.03 & $-0.77^{b}$ & 0.01 & $0.13^{b}$ & 0.01 & $0.59^{a}$ & 0.00 & $0.56^{b}$ & 0.01 \\
\hline$\Delta \pi_{t-3}^{+}$ & - & - & - & - & $-1.05^{a}$ & 0.00 & - & - & - & - & - & - \\
\hline$\Delta \pi_{t-4}^{+}$ & - & - & - & - & $-0.79^{a}$ & 0.00 & - & - & - & - & - & - \\
\hline$\Delta \pi_{t}^{-}$ & - & - & - & - & - & - & $-0.15^{c}$ & 0.06 & - & - & - & - \\
\hline$\Delta \pi_{t-1}^{-}$ & - & - & - & - & - & - & $-0.12^{b}$ & 0.04 & - & - & - & - \\
\hline$\Delta \pi_{t-2}^{-}$ & - & - & - & - & $-0.68^{b}$ & 0.02 & 0.06 & 0.43 & $-0.52^{b}$ & 0.04 & $-0.06^{b}$ & 0.01 \\
\hline$\Delta \pi_{t-3}^{-}$ & - & - & -0.75 & 0.00 & - & - & $-0.21^{a}$ & 0.00 & - & - & - & - \\
\hline$\Delta \pi_{t-4}^{-}$ & - & - & -0.65 & 0.00 & - & - & -0.07 & 0.32 & - & - & - & - \\
\hline$R^{2}$ & 0.74 & - & 0.87 & - & 0.82 & - & 0.94 & - & 0.81 & - & 0.89 & - \\
\hline $\operatorname{Adj} . R^{2}$ & 0.72 & - & 0.85 & - & 0.79 & - & 0.90 & - & 0.77 & - & 0.86 & - \\
\hline$D W$ & 0.37 & - & 0.83 & - & 0.54 & - & 1.20 & - & 0.70 & - & 0.85 & - \\
\hline$\chi_{S C}^{2}$ & 102.32 & 0.00 & 64.23 & 0.00 & 88.46 & 0.00 & 0.00 & 1.00 & 46.93 & 0.00 & 39.13 & 0.00 \\
\hline$\chi_{F F}^{2}$ & 0.45 & 0.49 & 12.64 & 0.00 & 30.11 & 0.00 & 0.62 & 0.43 & 1.16 & 0.28 & 0.63 & 0.42 \\
\hline$\chi_{N O R}^{2}$ & 0.15 & 0.92 & 1.08 & 0.58 & 2.27 & 0.32 & 3.88 & 0.14 & 4.72 & 0.09 & 1.85 & 0.39 \\
\hline$\chi_{H E T}^{2}$ & 17.83 & 0.21 & 30.10 & 0.18 & 22.90 & 0.34 & 33.17 & 0.55 & 9.18 & 0.95 & 17.75 & 0.40 \\
\hline$W_{L R}$ & 4.11 & 0.04 & 24.10 & 0.00 & 4.88 & 0.02 & 1.09 & 0.29 & 1.60 & 0.20 & 11.03 & 0.00 \\
\hline$W_{S R}$ & 4.11 & 0.04 & 26.72 & 0.00 & 4.88 & 0.02 & 20.95 & 0.00 & 8.10 & 0.00 & 6.31 & 0.01 \\
\hline$E G_{M A X}$ & -3.11 & 0.02 & -4.00 & 0.00 & -3.41 & 0.01 & -5.18 & 0.00 & -2.62 & 0.27 & -5.07 & 0.00 \\
\hline
\end{tabular}

Note: $\mathrm{a}, \mathrm{b}$ and c denote statistical significances at $1 \%, 5 \%$ and $10 \%$ levels respectively. $\chi_{S C}^{2}$ is Breusch-Godfrey LM test for autocorrelation, $\chi_{N O R}^{2}$ is the Jarque-Bera test for normality, $\chi_{F F}^{2}$ is Ramsey test for functional form misspecification, $\chi_{H E T}^{2}$ for white heteroscedasticity, $E G_{M A X}$ is largest value of the Engle-Granger residual-based ADF test. $W_{L R}$ and $W_{S R}$ are long and short-run Wald tests. All these additional diagnostic test results signify that there is no autocorrelation, misspecification of the optimum models and heterogeneity. The series are normally distributed and cointegrated. 
The test results in Panel A support the evidence of long-run Partial Fisher effects between 1995M1-2008M9 since the estimates of 1, 5 and 10-years treasury bond rates are significantly positive and are either lower or higher than 1 . Furthermore, 10 -years Treasury bond rates respond to the increases and decrease in inflation the most. In other words, the highest degree Fisher effect is detected on 10-years treasury bonds rates in the UK. Decreases in inflation affect the nominal interest rates more than increases. The effects of increases and decreases in inflation on the nominal interest rates rise when the maturity gets longer. Additionally, increases and decreases in inflation have asymmetric effects on all interest rates since the estimates of $\pi_{t}^{+}$and $\pi_{t}^{-}$are same in sign but different in size. However, the same test results in Panel A for 2008M10-2018M1 do not support the evidence of Fisher effects for any interest rates since the estimates of 1,5 and 10-years treasury bond rates are not significantly positive.

Nevertheless, the test results in Panel B support the new version of partial Fisher effects, as described in Section 1, in the short-run for different lags. While significantly positive $\Delta \pi_{t}^{+}$supports this type of partiality for 10-years treasury bond rates between $1995 \mathrm{M} 1-2008 \mathrm{M} 9$, significantly positive $\Delta \pi_{t}^{+}, \Delta \pi_{t^{-}}^{+}, \Delta \pi_{t^{-2}}^{+}$support the same types of partialities for 1, 5 and 10-years treasury bond rates between 2008M10-2018M1. In other words, the introduced version of partiality is valid only in the short-run (only from $\pi_{t}^{+}$), not in the long-run.

\section{Concluding Remarks}

This study approaches the Fisher effect from a different methodological perspective and thereby tries to describe and introduce a new version of the partial Fisher effect in this manner. To accomplish this, the nonlinear ARDL model recently introduced by Shin et al. (2004) is applied for the UK. This model and its decomposed variables allow us to re-examine the Fisher effect on a singular parametric manner. Hence, the model answers how increases and decreases in inflation rates in the UK separately affect 1-, 5-, and 10-year Treasury bond rates of this country in terms of the Fisher effect. The empirical findings indicate that long-run partial Fisher effects are valid for the UK only in the period of 1995M1-2008M9 and not for the period of 2008M10-2018M1. The positive relationship running from increases and decreases in inflation rates to the changes in interest rates are broken down after the 2008 global financial crisis. In the first period, interest rates are more sensitive to the decreases in inflation rates than increases (asymmetric effects). The higher degree partial Fisher effects are detected in longer maturity UK interest rates. The introduced version of partial Fisher effects is valid only in the short-run and only through increases in inflation on a singular paramet- 
ric manner. This means that while increases in inflation rates raise the nominal interest rates, decreases have no effect in the short-run. Additionally, this study shows the need for further empirical studies using new techniques in order to reexamine the Fisher effect and understand the mechanism between interest rates and inflation in greater depth. This is a matter of great importance, especially for countries like the UK, adapting inflation targeting policy by using interest rates as an operational target.

\section{Appendix}

The data of monthly nominal interest rates were obtained from the database of the Bank of England (BOE, 2018). The monthly inflation rates are measured by the percentage changes in the CPI index. The data of CPI were obtained from IMF Data Planet. 


\section{References}

1. Ajaz, T. (2019). Nonlinear Reaction functions: Evidence from India. Journal of Central Banking Theory and Practice, 1, 111-132.

2. Andrade, A. \& Clare, A. (1994). Is the UK Treasury Bill Rate a Good Proxy for Expected Inflation in the United Kingdom? Economics Letters, 45(3), pp. 335-341.

3. Bajo-Rubio, O., Díaz-Roldán, C.Y. \& Esteve, V. (2010). Testing the Fisher Effect in the Presence of Structural Change: A Case Study of the UK, 19662007. Economic Issues, 15(2), pp. 1-16.

4. BOE (2018). Bank of England. Statistics, https://www.bankofengland.co.uk/ statistics, (accessed 02 Februaury 2018)

5. Bayat, T., Kayhan, S. and Tasar, I. (2018). Re-Visiting Fisher Effect for Fragile Five Economies. Journal of Central Banking Theory and Practice, 7(1), 203218.

6. Fabris, N. (2018). Challenges for Modern Monetary Policy. Journal of Central Banking Theory and Practice, 2, 5-24.

7. Fahmy, Y.A.F. \& Kandil, M. (2003). The Fisher Effect: New Evidence and Implications. International Review of Economics and Finance, 12, pp. 451465.

8. Fisher, I. (1930). The Theory of Interest. New York: MacMillan.

9. Ghazali, N.A. \& Ramlee, S. (2003). A Long Memory Test of the Long-Run Fisher Effect in the G7 Countries. Applied Financial Economics, 13(10), pp.763-769.

10. Granville, B. \& Mallick, S. (2004). Fisher Hypothesis: UK Evidence over a Century. Applied Economics Letters, 11, pp.87-90.

11. IMF (2017). Data Planet, www.imf.org

12. Lardic, S. \& Mignon, V. (2003). Fractional Cointergration between Nominal Interest Rates and Inflation: A Re-Examination of the Fisher Relationship in the G7 Countries. Economic Bulletin. 3(14), pp.1-10.

13. Panopoulou, E. (2005). A Resolution of the Fisher Effect Puzzle: A Comparison of Estimators. Economics, Finance and Accounting Department Working Paper Series, No.1500205.

14. Peng, W. (1995). The Fisher Hypothesis and Inflation Persistence: Evidence from Five Major Industrial Countries. IMF Woking Paper, No: 95/118.

15. Praščević, A. and Ješić, M. (2019). Modeling Macroeconomic Policymakers' Interactions under Zero Lower Bound Environment: The New Keynesian Theoretical Approach. Journal of Central Banking Theory and Practice, 8(1), 5-38. 
16. Shin, Y., Yu, B. \& Greenwood-Nimmo, M. (2014). Modelling Asymmetric Cointegration and Dynamic Multipliers in a Nonlinear ARDL Framework. Festschrift in Honor of Peter Schmidt: Econometric Methods and Applications, eds. by R. Sickels and W. Horrace: Springer, 281-314.

17. Toyoshima, Y. \& Hamori, S. (2011). Panel Cointegration of the Fisher Effect: Evidence from the US, the UK and Japan. Economics Bulletin, 31(3), pp.2674-2682.

18. Yuhn, K. (1996). Is the Fisher Effect Robust? Further Evidence. Applied Economics Letters. 3, pp.41-44. 